EDITORIAL

\title{
A pesquisa em ensino de Ciências e Matemática no Brasil
}

As décadas de sessenta e setenta do século passado parecem ter sido propícias para que pesquisadores brasileiros das áreas de Ciências Exatas e Naturais, apoiados por colegas da Educação, Psicologia, História e Filosofia da Ciência, bem como outras áreas do conhecimento, passassem a se preocupar em estudar mais sistematicamente o ensino e a aprendizagem das Ciências e da Matemática, conforme mostram estudos que vêm sendo divulgados em diversas instâncias (NARDI, 2005, 2007; NARDI; ALMEIDA, 2004).

Os fatores que contribuíram para a constituição da área de Ensino de Ciências e Matemática no Brasil, bem como as origens e características da pesquisa que se faz nesta área, têm sido estudados com base em vários enfoques e referenciais e com o uso de diversas metodologias. $\mathrm{O}$ vasto conhecimento acumulado na área, fruto de trabalho de matemáticos, físicos, químicos, biólogos e outros profissionais que têm estudado academicamente essas questões, vem sendo sistematicamente mapeado e analisado por diversos autores (FERES, 2001, 2010; KAWAMURA; SALEM, 2008; LEMGRUBER, 1999; MEGID NETO, 1990, 2014; NARDI; ALMEIDA, 2004, 2007; NARDI; GONÇALVES, 2014; SCHENETZLER, 2002; SLONGO, 2004; TEIXEIRA, 2012).

Esses pesquisadores têm interlocução mediante representatividade em secretarias, seções de ensino ou comissões específicas de importantes sociedades científicas tradicionais - como, por exemplo, Sociedade Brasileira para o Progresso da Ciência (SBPC), Sociedade Brasileira de Física (SBF), Sociedade Brasileira de Química (SBQ), Sociedade Brasileira de Astronomia (SBA). E órgãos financiadores, como o Conselho Nacional de Desenvolvimento Científico e Tecnológico (CNPq); a Coordenação de Aperfeiçoamento de Pessoal de Nível Superior (CAPES); a Financiadora de Estudos e Projetos (FINEP) e fundações de amparo à pesquisa de diversos estados brasileiros, como é o caso da Fundação de Amparo à Pesquisa no Estado de São Paulo (FAPESP), que têm dedicado apoio e financiamento regular para o desenvolvimento de projetos de pesquisa e extensão nessa área.

As características inter ou multidisciplinares que esse tipo de pesquisa demanda fizeram entender, logo cedo, que conhecer profundamente apenas os conteúdos das disciplinas de Ciências e Matemática não bastava para se avançar no estudo das particularidades que os processos de ensino e de aprendizagem das Ciências demandam. Essa preocupação foi logo sentida por grupos de pesquisadores, que entenderam a necessidade de se dedicarem integralmente a esses estudos, oportunizando o surgimento, nas décadas de oitenta e noventa, de associações específicas de ensino, como a Sociedade Brasileira de Educação Matemática (SBEM), a Sociedade Brasileira de Ensino de Biologia (SBenBio) e a Associação Brasileira de Pesquisa em Educação em Ciências (Abrapec).

Desde o início também, alguns dilemas rondam pesquisadores e professores que atuam na área: devemos estudar ciências, matemática e tecnologias para formar novos cientistas ou para 'alfabetizar' ou 'aculturar cientificamente' cidadãos que fazem uso da ciência em seu cotidiano? A pesquisa nessa área deve ser realizada, ou definida, na academia, ou com o envolvimento de 
professores em exercício nas diversas instâncias de ensino? E deve ser realizada em institutos específicos de ciências, em faculdades de educação ou em outras instâncias? Como considerar resultados da pesquisa no ensino de sala de aula, tendo em vista a formação de professores que atuam no ensino superior e na educação básica e as condições de trabalho que lhes são oferecidas?

Essas discussões vêm sendo contempladas em publicações, como, por exemplo, Formação da área de ensino de ciências no Brasil: fatores que contribuíram para a constituição e consolidação da pesquisa e suas características segundo destacados pesquisadores brasileiros, de Nardi e Almeida (2014), resultante de estudo organizado com base em respostas dadas a questões formuladas pelos autores a pesquisadores brasileiros, considerados por seus pares como importantes na constituição dessa área no Brasil.

Este estudo mostra, também, que um dos fatores considerados importantes na constituição da área, foi a instituição de sua pós-graduação. Diversos autores mostram essa trajetória, iniciada com dois dos primeiros programas de pós-graduação na área de Ensino de Ciências e Matemática que surgiram no país nessa época, ao lado, por exemplo, dos programas de Ensino de Física implantados nos institutos de Física da Universidade de São Paulo (USP) e da Universidade Federal do Rio Grande do Sul (UFRGS). O primeiro desses programas, relatado por D'Ambrosio (2014), no capítulo intitulado Uma sintese do programa experimental de mestrado em ensino de ciências e matemática da UNICAMP/OEA/MEC (1975 a 1984) mostra sua experiência como coordenador deste programa, ocorrido entre 1974 e 1984 na Universidade Estadual de Campinas (UNICAMP). Outro desses pioneiros, cujas memórias são relatadas por Bicudo (2014) sob o título A pós-graduação em educação matemática de Rio Claro: historiando sua trajetória, é o Programa de Pós-Graduação em Educação Matemática da Universidade Estadual Paulista (UNESP), um dos primeiros nesta área no país, cuja história contabiliza hoje cerca de trinta anos de existência, com centenas de mestres e doutores formados e atuando no Brasil e no exterior.

A expressiva contribuição da pesquisa em Ensino de Ciências e Matemática para a educação no Brasil, em todos os níveis, também é analisada a partir de referenciais teóricos específicos. Em Origens e desenvolvimento do campo de pesquisa em educação em ciências no Brasil, Megid Neto (2014) discute o que chama de 'elementos fundantes' do campo de conhecimento em Educação em Ciências no Brasil, procurando mostrar seu desenvolvimento até os dias atuais. O estudo destaca o impulso da pesquisa, com a criação da área (46) de Ensino de Ciências e Matemática da CAPES, em setembro de 2000. Em outro estudo, intitulado Educação em ciências no Brasil: uma análise de sua constituição e institucionalização sob o aporte da teoria de Bourdieu, Feres (2010) busca elementos da teoria de Bourdieu e de outros autores para explicar a constituição e institucionalização da área no Brasil. Com base em pesquisas e estudos realizados nos últimos anos, infográficos mostram a evolução da pós-graduação em Ensino de Ciências. Os gráficos procuram ilustrar o "movimento dos pesquisadores em torno de ações importantes para a constituição e institucionalização da área, marcando o período de 2000 como a década correspondente à consolidação e expansão de programas de pós no país” (FERES, 2010, p. 74). A análise da distribuição geográfica dos programas e cursos de pós-graduação existentes até então chama a atenção para um problema, não só desta área, mas também de quase todas as pós-graduações brasileiras: a concentração de programas e de cursos na região sudeste do país. O levantamento de eventos ocorridos desde décadas anteriores e a apresentação de linhas de pesquisa e áreas de concentração de programas e grupos de pesquisa no país são contemplados neste estudo, que se mostra bastante completo e importante para as memórias da área.

Em recente publicação, intitulada Avaliação dos programas de pós-graduação na área de ensino de ciências e matemática no triênio 2007-2009, Nardi e Gonçalves (2014) procuram resumir e interpretar dados sobre o avanço dos programas nesse período, destacando a evolução da área desde sua institucionalização na CAPES, no ano 2000. Coordenada por esses docentes e 
produzida conjuntamente por uma equipe formada por 18 pesquisadores, então coordenadores de programas de pós-graduação espalhados por todas as regiões do país, a avaliação trienal desse período gerou e divulgou relatório minucioso, importante para situar o avanço da área e projetar o futuro da pesquisa em Ensino de Ciências e Matemática. Essa avaliação trienal, conforme consta do relatório da CAPES,

[...] foi uma etapa conclusiva de um processo de avaliação continuada que se iniciou no começo do triênio, em 2007, e cujas etapas intermediárias constituíram-se de diversas reuniões com coordenadores de pós-graduação, avaliações realizadas por comissões designadas para estratificar periódicos, livros e eventos, bem como consultas permanentes às comunidades docente e discente que integram os programas da área. (NARDI; GONÇALVES, 2014, p. 317)

O texto apresenta dados importantes como, por exemplo, que a área de Ensino de Ciências e Matemática, instituída no ano 2000, evoluiu de sete para sessenta programas de pós-graduação e 78 cursos no final de 2009. E, ainda, que a análise desses dados pode oportunizar importantes reflexões sobre a pesquisa na área, subsidiando tomadas de decisões para as próximas décadas.

O avanço que a pós-graduação em Ensino de Ciências e Matemática no país experimentou neste período parece ter sido importante para que a CAPES, a partir de 2010, tenha ampliado a área 46 de avaliação, que passou a ser chamada de Área de Ensino. A forma com que foi conduzido esse processo, entretanto, suscitou intensos debates entre pesquisadores e associações da área e os reflexos dessa decisão ainda precisam ser analisados com mais profundidade pela comunidade de pesquisadores.

Outra questão a ser estudada pela comunidade de pesquisadores na área refere-se aos efeitos das políticas de governo que recentemente implantaram mestrados profissionais nacionais em rede, como os primeiros, na área de ensino de Matemática (ProfMat) e de ensino de Física (Profis), bem como outros já anunciados. No caso específico da Física, as comissões de ensino e de pesquisa promoveram amplo debate, sem aparentemente chegarem a consenso sobre as questões da natureza, da abrangência e da interferência desses programas em outros já estabelecidos anteriormente em diversas universidades brasileiras.

Dentre vários outros pontos que vêm sendo questionados, no caso específico do ensino da Física, um deles baseia-se em estudos que têm mostrado que os professores licenciados em Física, em serviço na educação básica, concluintes de mestrados profissionais em ensino de Física, acabam por abandonar o magistério para ingresso na pós-graduação, em nível de doutorado acadêmico, ou ingressam no magistério superior. Estudo realizado por Kussuda (2012) mostra que as condições de trabalho na educação básica, a remuneração acanhada e outros fatores, são apontados como causas desse problema. Este fato é agravado quando se constata que a crônica falta de professores de Física na educação básica não tem sido resolvida nas últimas décadas. Dessa forma, uma agenda de estudos de avaliação dessas políticas educacionais, tanto as específicas sobre a pós-graduação, bem como as de caráter mais geral, sobre a educação no país, mostra-se urgente. Embora possam aparentemente ser importantes, medidas isoladas não devem ser tomadas desvinculadas de outras políticas públicas; precisam ser pensadas em conjunto.

O acúmulo de conhecimento produzido pela pesquisa acadêmica, bem como a experiência de ações de extensão derivadas da pesquisa junto aos ambientes educacionais e outros não-formais devem ser respeitados na implementação dessas políticas públicas. Desconsiderar 
os resultados dessa produção, ou tomar medidas a partir de opiniões de leigos pode se constituir em 'recomendações vazias', conforme argumenta Almeida (2012), cujas consequências pouco têm contribuído para a melhoria do ensino no país.

\section{Roberto Nardi \\ Departamento de Educação, Faculdade de Ciências, Universidade Estadual Paulista (UNESP), Campus Universitário, Vargem Limpa, Caixa Postal 473, CEP. 17.033-360, Bauru, SP, Brasil. E-mail: <nardi@fc.unesp.br>}

\section{Referências}

ALMEIDA, M. J. P. M. Meio século de educação em ciências: foco nas recomendações ao professor de física. São Paulo: LF Editorial, 2012.

BICUDO, M. A. V. A pós-graduação em educação matemática de Rio Claro: historiando sua trajetória. In: NARDI, R.; GONÇALVES, T. V. O. A pós-graduação em ensino de ciências e matemática no Brasil: origens, características, programas e consolidação da pesquisa na área. São Paulo: Livraria da Física, 2014. p. 85-97.

D'AMBRÓSIO, U. Uma síntese do programa experimental de mestrado em ensino de ciências e matemática da UNICAMP/OEA/MEC (1975 a 1984). In: NARDI, R.; GONÇALVES, T. V. O. A pós-graduação em ensino de ciências e matemática no Brasil: origens, características, programas e consolidação da pesquisa na área. São Paulo: Livraria da Física, 2014. p. 56-84.

FERES, G. G. Da organização ao compartilhamento do conhecimento científico gerado na área de educação em ciências no Brasil: uma contribuição à criação de facilidades de acesso e uso da informação. 2001. 150 f. Dissertação (Mestrado em Educação para a Ciência) - Faculdade de Ciências, Universidade Estadual Paulista, Bauru, 2001.

A pós-graduação em ensino de ciências no Brasil: uma leitura a partir da teoria de Bourdieu. 2010. 337 f. Tese (Doutorado em Educação para a Ciência) - Faculdade de Ciências, Universidade Estadual Paulista, Bauru, 2010.

KAWAMURA, M. R. D.; SALEM, S. Ensino de física no Brasil: dissertações e teses (1996-2005): catálogo analítico. São Paulo: PROFIS: IFUSP, 2008.

KUSSUDA, S. R. A escolha profissional de licenciados em física de uma universidade pública. 2012. 184 f. Dissertação (Mestrado em Educação para a Ciência) - Faculdade de Ciências, Universidade Estadual Paulista, Bauru, 2012. 
LEMGRUBER, M. S. A educação em ciências físicas e biológicas a partir das teses e dissertações (1981 a 1995): uma história de sua história. 1999. 184 f. (Doutorado em Educação) - Faculdade de Educação, Universidade Federal do Rio de Janeiro, Rio de Janeiro, 1999.

MEGID NETO, J. Origens e desenvolvimento do campo de pesquisa em educação em ciências no Brasil. In: NARDI, R.; GONÇALVES, T. V. O. A pós-graduação em ensino de ciências e matemática no Brasil: origens, características, programas e consolidação da pesquisa na área. São Paulo: Livraria da Física, 2014. p. 98-139.

Pesquisa em ensino de física do $2^{\circ}$ grau no Brasil: concepção e tratamento de problemas em teses e dissertações. 1990. 296 f. Dissertação (Mestrado em Educação) - Faculdade de Educação, Universidade Estadual de Campinas, Campinas, 1990.

NARDI, R. A área de ensino de ciências no Brasil: fatores que determinaram sua constituição e suas características segundo pesquisadores brasileiros. 2005. 170f. Tese (Livre- Docência) - Faculdade de Ciências, Universidade Estadual Paulista, Bauru, 2005.

ARDI, R. (Org.) A pesquisa em ensino de ciências no Brasil: alguns recortes. São Paulo: Escrituras, 2007.

NARDI, R.; ALMEIDA, M. J. P. M. Formação da área de ensino de ciências: memórias de pesquisadores no Brasil. Revista Brasileira de Pesquisa em Educação em Ciências, Porto Alegre, v. 4, n. 11, p. 90-100, 2004.

Formação da área de ensino de ciências no Brasil: fatores que contribuíram para a constituição e consolidação da pesquisa e suas características segundo destacados pesquisadores brasileiros. In: NARDI, R.; GONÇALVES, T. V. O. A pós-graduação em ensino de ciências e matemática no Brasil: origens, características, programas e consolidação da pesquisa na área. São Paulo: Livraria da Física, 2014. p. 17-55.

. Investigações em ensino de ciências no Brasil segundo pesquisadores da área: alguns fatores que lhe deram origem. Pro-Posições, Campinas, v. 18, n. 1, p. 213-226, jan./abr. 2007.

NARDI, R.; GONÇALVES, T. V. O. A pós-graduação em ensino de ciências e matemática no Brasil: memórias, programas e consolidação da pesquisa na área São Paulo: Livraria da Física, 2014.

SCHNETZLER, R. P. A pesquisa em ensino de química no Brasil: conquistas e perspectivas. Química Nova, São Paulo, v. 25, supl. 1, p. 14-24, 2002.

SLONGO, I. I. P. A produção acadêmica em ensino de biologia: um estudo a partir de teses e dissertações. 2004. 364 f. Tese (Doutorado em Educação) - Centro de Ciências da Educação, Universidade Federal de Santa Catarina, Florianópolis, 2004.

TEIXEIRA, P. M. M. T. (Org.). 35 anos da produção acadêmica em ensino de biologia no Brasil: catálogo analítico de dissertações e teses (1972-2006). Vitória da Conquista: Edições UESB, 2012. 